\title{
Activated mammalian target of rapamycin is a potential therapeutic target in gastric cancer
}

\author{
Da-zhi Xu ${ }^{1,2+}$, Qi-rong Geng ${ }^{1,3+}$, Ying Tian ${ }^{1}$, Mu-yan Cai ${ }^{1,4}$, Xin-juan Fang ${ }^{5}$, You-qing Zhan ${ }^{1,2^{*}}$, Zhi-wei Zhou ${ }^{1,2}$, \\ Wei Li ${ }^{1,2}$, Ying-bo Chen ${ }^{1,2}$, Xiao-wei Sun ${ }^{1,2}$, Yuan-xiang Guan ${ }^{1,2}$, Yuan-fang Li ${ }^{1,2}$, Tong-yu Lin ${ }^{1,3^{*}}$
}

\begin{abstract}
Background: The mammalian target of rapamycin (mTOR) plays a key role in cellular growth and homeostasis. The purpose of our present study is to investigate the expression of activated mTOR (p-mTOR) in gastric cancer patients, their prognostic significance and the inhibition effect of RAD001 on tumor growth and to determine whether targeted inhibition of mTOR could be a potential therapeutic strategy for gastric cancer.

Methods: The expression of p-mTOR was detected in specimens of 181 gastric cancers who underwent radical resection (R0) by immunohistochemistry. The correlation of p-mTOR expression to clinicopathologic features and survival of gastric cancer was studied. We also determined the inhibition effect of RAD001 on tumor growth using BGC823 and AGS human gastric cancer cell lines.

Results: Immunostaining for p-mTOR was positive in 93 of 181 (51.4\%) gastric cancers, closely correlated with lymph node status and pTNM stage. Patients with p-mTOR positive showed significantly shorter disease-free survival (DFS) and overall survival (OS) rates than those with p-mTOR-negative tumors in univariable analyses, and there was a trend toward a correlation between p-mTOR expression and survival in multivariable analyses. RAD001 markedly inhibited dose-dependently proliferation of human gastric carcinoma cells by down-regulating expression of p70s6k, p-p70s6k, C-myc, CyclinD1 and Bcl-2, up-regulating expression of P53.
\end{abstract}

Conclusions: In gastric cancer, p-mTOR is a potential therapeutic target and RAD001 was a promising treatment agent with inducing cell cycle arrest and apoptosis by down-regulating expression of C-myc, CyclinD1 and Bcl-2, up-regulating expression of P53.

\section{Background}

Gastric carcinoma is the fourth most common cancer and the second leading cause of cancer-related death worldwide, including 1 million new cases per year throughout the world [1]. About $60 \%$ of new cases of gastric cancer occur in eastern Asia [2], especially in China. Surgical resection is the most effective treatment for gastric cancer and the efficacy of chemotherapy remains limited [3]. Many studies have indicated that the depth of invasion and the number of metastatic lymph nodes are the most important powerful predictors of survival for gastric cancer patients $[4,5]$. For example, in previous studies [6,7], we have found

\footnotetext{
* Correspondence: YQ_Zhan@21cn.com; tongyulin@hotmail.com

+ Contributed equally

'State Key Laboratory of Oncology in South China, Guangzhou 510060,

China

Full list of author information is available at the end of the article
}

positive lymph node ratio is an independent prognostic indicator after D2 resection and intraperitoneal chemotherapy may be beneficial to gastric cancer patients. However, a fundamental step toward improving clinical outcome lies in the increased understanding of the tumor biological behavior, which may help to identify the possible targets for individual therapy $[8,9]$.

In recent years, molecularly based approaches for treatment in gastric cancer has been given great concern. Several articles have described some potential molecular targets for therapy in gastric cancer, such as epidermal growth factor receptor (EGFR) [10-13], vascular endothelial growth factor (VEGF) [14], recepteur d'origine nantais (RON) [15].

The mammalian target of rapamycin (mTOR) is a new potential molecular target for anticancer therapy. Its expression has been demonstrated in various cell lines and tumor specimens, such as liver neoplasms [16], 
breast cancer [17], biliary tract adenocarcinoma [18], and cervical cancer $[19,20]$. These studies showed that mTOR expression was associated with poor clinical prognosis. Lang et al [21]. have also observed mTOR activation in human gastric cancer in vitro and in vivo. They indicated mTOR is frequently activated in human gastric cancer. Recently, an orally bioavailable derivative of rapamycin, RAD001 (everolimus; Novartis Pharma AG), has been developed. A phase III trial revealed treatment with everolimus prolongs progression-free survival in patients with metastatic renal cell carcinoma that had progressed on other targeted therapies [22]. RAD001 has also been shown to inhibit the proliferation of tumor cell growth in some carcinomas [23,24]. But the role of RAD001 in gastric cancers cell is not clear.

The aims of this study were to further analyze the relationships the mTOR expression with the prognosis value of activated mTOR (p-mTOR), the effect of RAD001 on the growth and cell cycle of human gastric cancer cells in vitro and determine whether gastric cancer is a good candidate for target therapy with mTOR inhibitors.

\section{Methods}

\section{Patients studied}

This retrospective study consisted of 181 patients who underwent radical resection (R0) for histologically confirmed gastric carcinoma from Cancer Center of Sun Yat-sen University between January 1997 and December 2002. All patients with histologically confirmed adenocarcinoma of the stomach had undergone either proximal partial gastrectomy, distal partial gastrectomy or total gastrectomy. Ethical approval was obtained from Sun Yat-sen University Cancer Center research ethics committee.

Those with adequate histological material and complete clinical data were eligible for inclusion. The eligibility criteria also included histologically confirmed R0 resection, which was defined as no macroscopic and microscopic residual tumor and postoperative survival time $\geq 6$ months. Patients with distant metastases and carcinoma of gastric stump after resection for benign disease were excluded from the study. The reason is that the survival of patients with distant metastases is often affected by many other factors, such as preoperative chemotherapy or obstruction.

All patients had follow-up after surgery at 6 to 12 month intervals; the final date of follow-up was December 2008. Median follow up period was 50 (mean: 50.66; range 10 to 128 ) months for all patients, and 74 months (mean: 72.80; range 27 to 128) for survival. Median duration of follow up was 40 (mean: 43.71; range 11 to 125) for patients who had tumors of $\mathrm{p}$-mTOR positive expression, and 60.5 months (mean: 58.01; range 10 to
128) for negative expression. Survival was calculated from the date of diagnosis until the date of death or last follow-up.

\section{Specimen collection and Immunostaining for p-mTOR}

All tumor specimens were obtained from surgically resected gastric cancers before adjuvant therapy. Formalin-fixed, paraffin-embedded tissue blocks were stored at room temperature identified by an identification number. Five- $\mu$ m-thick tissue sections were cut from the paraffin blocks, deparaffinized in xylene, and rehydrated. Antigenic retrieval was processed with sodium citrate. The slides were then incubated in $0.3 \% \mathrm{H}_{2} \mathrm{O}_{2}$ for 10 min, and blocked in $1 \%$ bovine serum albumin for 60 min followed by a rabbit monoclonal antibody specific for p-mTOR (Phospho-mTOR, Ser2448, 49F9; Cell Signaling Technology) at $4^{\circ} \mathrm{C}$ overnight, and then stained with 3,3-diaminobenzidine. After visualization of immunoreactivity, the sections were counterstained with hematoxylin and then mounted.

\section{Evaluation of Immunohistochemical Staining}

The immunostained sections were evaluated and tissues from human prostate adenocarcinomas served as positive control. According to recently described criteria for rating $\mathrm{mTOR}$ expression, staining intensity was determined as 0 (absent), 1 (weak), and 2 (strong) and expression levels of the biomarkers were semiquantified using an immunohistochemistry score (range, 0-200) calculated by multiplying staining intensity with the percentage of positive tumor cells[18]. Patients with an immunohistochemistry score of $\leq 20$ were considered as p-mTOR-negative and those with a score of $>20$ as pmTOR-positive. All slides were independently assessed by two independent pathologists without any knowledge of the patients' clinical information. When the opinions of the two evaluators were different, agreement was reached by careful discussion.

\section{Cell lines and culture conditions}

Human gastric cancer cell lines BGC823 and AGS (ATCC Number: CRL-1739) which are poorly differentiated were gifts from Peking University School of Oncology (Beijing, P.R. China.) [25]. The cell lines were maintained in RPMI 1640 medium (Invitrogen) supplemented with $10 \%$ fetal bovine serum (Hyclone), penicillin $(100$ units $/ \mathrm{mL})$ and streptomycin $(100$ units $/ \mathrm{mL})$ at $37^{\circ} \mathrm{C}$ and $5 \% \mathrm{CO} 2$ in a humidified incubator.

\section{Cell viability assay}

To analyze the effect of RAD001 on human gastric cancer cells, cell viability was determined by MTT assay. RAD001 was provided by Novartis Pharma (Basel, Switzerland). For the viability assay, logarithmically growing 
cells were stimulated with various doses of RAD001 (0, $5,10,20$ and $40 \mu \mathrm{M})$. At the end of culture period, 20 $\mu \mathrm{L}$ of tetrazolium dye 3-(4,5-dimethylthiazole-2-yl)-2,5diphenyltetrazolium bromide (MTT) (Sigma, USA) solution at $0.2 \mathrm{mg} / \mathrm{ml}$ in PBS was added, the optical density at $490 \mathrm{~nm}$ (OD490) was determined by using an enzyme-linked immunosorbent assay (ELISA) reader. Mean values were calculated from triplicate cultures.

\section{Cell cycle analysis}

Cells were collected and fixed in $70 \%$ ethanol overnight at $4{ }^{\circ} \mathrm{C}$. Cells were then washed and stained with propidium iodide (PI) (Sigma) $5 \mu \mathrm{g} / \mathrm{mL}$. After $30 \mathrm{~min}$ at room temperature protected from light, the cells were analysed via flow cytometry using a Becton Dickinson FACScan.

\section{Annexin V assay}

The samples were washed with phosphate-buffered saline (PBS) and using Annexin V-fluorescein isothiocyanate (FITC) and PI staining for determination of phosphatidylserine exposure on the outer plasma membrane. After incubation for $30 \mathrm{~min}$ at room temperature protected from light, the samples were quantified by flow cytometry, using a Becton Dickinson FACScan.

\section{Reverse transcription-PCR}

Total RNA was extracted by using TRIzol method. RNA was reversely transcripted using a commercially available kit (Fermentas, USA). The mixture ( $25 \mu \mathrm{L}$ total) for PCR consisted of $0.5 \mu \mathrm{l}$ cDNA, $0.5 \mathrm{U}$ Taq DNA polymerase, $2.5 \mu \mathrm{l}$ of $10 \times$ PCR buffer, $2.5 \mathrm{mM}$ dNTP mixture, and 50 pM sense and antisense primers each. CyclinD1 and Cmyc were analyzed by following primers: CyclinD1 5'GAACAGAAGTGCGAGGAGGAG3' and reverse primer 5'AGGCGGTAGTAGGACAGGAAG3'; C-myc, 5' CGAGCTGCTGGGAGGAGACAT3' and 5' AGCCGCCCACTTTTGACA GG3' Actin: 5'GGCACCCAGCACAATGAA 3' and 5' TAGAAGCATTTGCGGTGG 3'.

\section{Cell lysate and Western blot analysis}

Cells were lysed in lysis buffer and the concentration of protein was determined by the Bradford dye method (Bio-Rad Laboratories). Equal amounts of cell extract were subjected to SDS-PAGE and transferred to PVDF membrane (Bio-Rad). Western blot analyses were done with various specific primary antibodies. Antibodies recognizing phospho-p70S6K (Thr389), p70S6K, phospho-mTOR(Ser2448), Bcl-2 and p53 were from Cell Signaling.

\section{Statistical analyses}

The primary end point of our study was overall survival (OS). It was defined as the period between the time of surgery and death. Disease-free survival (DFS) was the time between the time of surgery and relapse or tumor-related death. It was analyzed as a secondary end point. The association of $\mathrm{p}$-mTOR expression with various clinicalopathologic features was analyzed using the chi-square test. Cumulative survival and diseasefree survival were estimated by the Kaplan-Meier method. The log-rank test was used to evaluate the statistical significance of differences between survival curves. A Cox proportional hazard model (backward, stepwise) for multivariable analysis was applied for factors that achieved significance in univariable analysis. Statistical analysis was performed using SPSS software (version 13 for Windows; SPSS, Chicago, IL). Differences at $\mathrm{P}<.05$ were considered to be statistically significant.

\section{Results}

\section{Clinicopathologic features}

A total of 181 patients were enrolled in this study. The median age was 59 years (range, 23-83 years). The clinicopathologic characteristics of the study population are summarized in Table 1. 129 patients were male and 52 female. 77 of 181 tumors (42.5) were from the upper stomach, 74 of 181 patients (40.9\%) were from the lower part of the stomach, and the remaining tumors were from the middle and whole body of the stomach. 118 of $181(65.2 \%)$ patients' tumor size were $>4 \mathrm{~cm}$, and $63(34.8 \%)$ were $\leq 4 \mathrm{~cm}$. In accordance with World Health Organization criteria, 4 of 181 tumors $(2.2 \%)$ were well differentiated, 55 of 181 tumors (30.4\%) were moderately differentiated, 116 were poorly differentiated, and 6 were undifferentiated. Post-operative surgical stage was classified according to the 2002 UICC/AJCC classification [26].

129 of 181 patients (71.2\%) had more advanced $\mathrm{T}$ stage disease (PT3+PT4), and 137 patients (75.7\%) had lymph node metastasis. Totally patients of stage I-IV were $26,47,100$ and 8 cases, respectively.

\section{p-mTOR expression in gastric cancer}

Immunostaining of $\mathrm{p}$-mTOR was cytoplasmatic and partly membranous. Figure 1 shows representative examples of $\mathrm{p}-\mathrm{mTOR}$ immunostaining. The normal gastric mucosa is negative for $\mathrm{p}$-mTOR. Of the 181 patients, 93 (51.4\%) were p-mTOR-positive tumors.

\section{Survival analysis}

Patients with p-mTOR positive gastric cancer showed significantly shorter disease-free and overall survival rates than those with $\mathrm{p}-\mathrm{mTOR}$ negative gastric cancer (DFS, $48.9 \%$ versus $30.1 \%$; $=.006$; OS, $51.1 \%$ versus $34.4 \%$; $\mathrm{p}=.011$; Table 2; Figure 2A, B). Univariable analysis revealed that survival time also decreased with 
Table 1 Clinicopathologic correlation of p-mTOR expression in gastric cancer

\begin{tabular}{|c|c|c|c|c|}
\hline \multirow[t]{2}{*}{ Factors } & \multirow{2}{*}{$\begin{array}{l}\text { All } \\
\text { patients } \\
N=181 \\
(\%)\end{array}$} & \multicolumn{2}{|c|}{ No. of patients (\%) } & \multirow[t]{2}{*}{$P$} \\
\hline & & $\begin{array}{l}\text { mTOR } \\
\text { negative }\end{array}$ & $\begin{array}{l}\text { mTOR } \\
\text { positive }\end{array}$ & \\
\hline$\overline{\text { Age(y) }}$ & & & & .256 \\
\hline$<60$ & $95(52.5)$ & $50(56.8)$ & $45(48.4)$ & \\
\hline$\geq 60$ & $86(47.5)$ & $38(43.2)$ & $48(51.6)$ & \\
\hline Sex & & & & .926 \\
\hline Male & 129(71.3) & 63(71.6) & $66(71.0)$ & \\
\hline Female & $52(28.7)$ & $25(28.4)$ & $27(29.0)$ & \\
\hline Site & & & & .053 \\
\hline Upper & $77(42.5)$ & $33(37.5)$ & $44(47.3)$ & \\
\hline Middle & $28(15.5)$ & 10(11.4) & 18(19.4) & \\
\hline lower & 74(40.9) & 43(48.9) & $31(33.3)$ & \\
\hline Diffuse & $2(1.1)$ & $2(2.3)$ & $0(0.0)$ & \\
\hline Tumor size & & & & .172 \\
\hline$\leq 4 \mathrm{~cm}$ & 63(34.8) & $35(40.0)$ & $28(30.1)$ & \\
\hline$>4 \mathrm{~cm}$ & 118(65.2) & $53(60.0)$ & $65(69.9)$ & \\
\hline Borrmann type & & & & .398 \\
\hline Early stage & $7(3.9)$ & $6(6.8)$ & $1(1.1)$ & \\
\hline । & $4(2.2)$ & $2(2.3)$ & $2(2.1)$ & \\
\hline$\|$ & 65(35.9) & $31(35.2)$ & $34(36.6)$ & \\
\hline III & 101(55.8) & 47(53.4) & $54(58.1)$ & \\
\hline IV & $4(2.2)$ & $2(2.3)$ & $2(2.1)$ & \\
\hline grading & & & & .999 \\
\hline 1 & $4(2.2)$ & $2(2.3)$ & $2(2.1)$ & \\
\hline 2 & $55(30.4)$ & 27(30.7) & 28(30.1) & \\
\hline 3 & 116(64.1) & $56(63.6)$ & $60(64.5)$ & \\
\hline 4 & $6(3.3)$ & $3(3.4)$ & $3(3.3)$ & \\
\hline $\begin{array}{l}\text { Pathologic T } \\
\text { classification }\end{array}$ & & & & .168 \\
\hline $\mathrm{T} 1$ & $17(9.4)$ & 12(13.6) & $5(5.4)$ & \\
\hline $\mathrm{T} 2$ & $35(19.3)$ & 18(20.5) & 17(18.3) & \\
\hline T3 & 119(65.7) & $55(62.5)$ & $64(68.8)$ & \\
\hline T4 & $10(5.5)$ & $3(3.4)$ & $7(7.5)$ & \\
\hline Pathologic $N$ status & & & & .008 \\
\hline $\mathrm{N}$ negative & $44(24.3)$ & 29(33.0) & 15(16.1) & \\
\hline $\mathrm{N}$ positive & 137(75.7) & $59(67.0)$ & 78(83.9) & \\
\hline $\begin{array}{l}\text { Pathologic stage } \\
\text { (pTNM) }\end{array}$ & & & & .026 \\
\hline । & $26(14.4)$ & 17(19.3) & $9(9.7)$ & \\
\hline$\|$ & $47(26.0)$ & 28(31.8) & $19(20.4)$ & \\
\hline III & $100(55.2)$ & $41(46.5)$ & $59(63.4)$ & \\
\hline IV & $8(4.4)$ & $2(2.3)$ & $6(6.5)$ & \\
\hline
\end{tabular}

higher pT classification (DFS, $\mathrm{p}=.001$; OS, $\mathrm{P}=.005$ ), lymph node metastasis (DFS, $\mathrm{p}<.0001 ; \mathrm{OS}, \mathrm{P}=.001$ ) and advanced pTNM stage (DFS, $\mathrm{p}<.001$; OS, $\mathrm{P}=$ $.001)$. There was no association between DFS or OS and age, sex or tumor size.

In multivariable analysis, lymph node metastasis (DFS, $\mathrm{p}=.018$; OS, $\mathrm{P}=.038)$ and $\mathrm{pT}$ stage $(\mathrm{DFS}, \mathrm{p}=.018$;
OS, $\mathrm{P}=.046)$ were significant independent prognostic factor for survival time. In addition, multivariable analysis (Table 3) also indicated a trend toward a correlation between p-mTOR expression and decreased survival, but the trend did not reach statistical significance (DFS, $\mathrm{p}=.059 ;$ OS, $\mathrm{P}=.070$ ).

\section{RAD001 inhibits proliferation and prevents p70S6K phosphorylation}

To investigate the effects of RAD001 on the proliferation of human gastric cancer cell lines BGC823 and AGS, we performed proliferation assays with 48-hour exposure to RAD001. As a result, RAD001 generates significant inhibition on both cell lines in a dose-dependent manner. (Figure 3A).

Western blot experiments were performed with RAD001 at 0, 5, 10, $20 \mu \mathrm{M}$ for $48 \mathrm{~h}$. P70s6 kinase is an important downstream target of mTOR and its mTORdependent phosphorylation allows translation of ribosomal proteins. We examined the phosphorylation status of downstream target p70s6K by immunoblotting. As shown in Figure 3B, we found that treatment of both cell lines BGC823 and AGS with RAD001 significantly prevent phosphorylation of p70s6K in a dose-dependent manner.

\section{RAD001 induces G0/G1 cell cycle arrest and apoptosis in gastric cancer cells}

To determine if the suppression in cell proliferation were due to G0/G1-phase arrest or apoptosis, cell-cycle distribution was analyzed by FCM. Figure 4 showed that treatment of BGC823 cells of with RAD001 for 48 hours resulted in a robust G1 arrest and promoted apoptosis. With the increasing dose of RAD001, more and more cells remained in G1-phase, while cell cycle progression into $\mathrm{S}$ phase was decreasing (Figure 4A). RT-PCR analysis revealed RAD001 dose-dependently decreased the mRNA level of Cyclin D1 and C-myc (Figure 4B).

Annexin- $\mathrm{V}$ assays showed that RAD001 significantly induced apoptosis in BGC823 cells. An increase in apoptosis rate was analyzed by FCM with the increase of the dose (Figure 4C). Western blot analysis showed RAD001 dose-dependently decreasing the protein level of Bcl-2 and increasing the protein level of p53 (Figure 4D). Similar results were observed in AGS cells (data not shown).

\section{Discussion}

The mammalian target of rapamycin (mTOR) was discovered in the early $1990 \mathrm{~s}$ in studying the mechanism of action of rapamycin, which was originally found as an antifungal agent and was later recognized as anticancer properties [27]. As a Ser/Thr protein kinase, mTOR plays a key role in cellular growth and homeostasis [28]. 

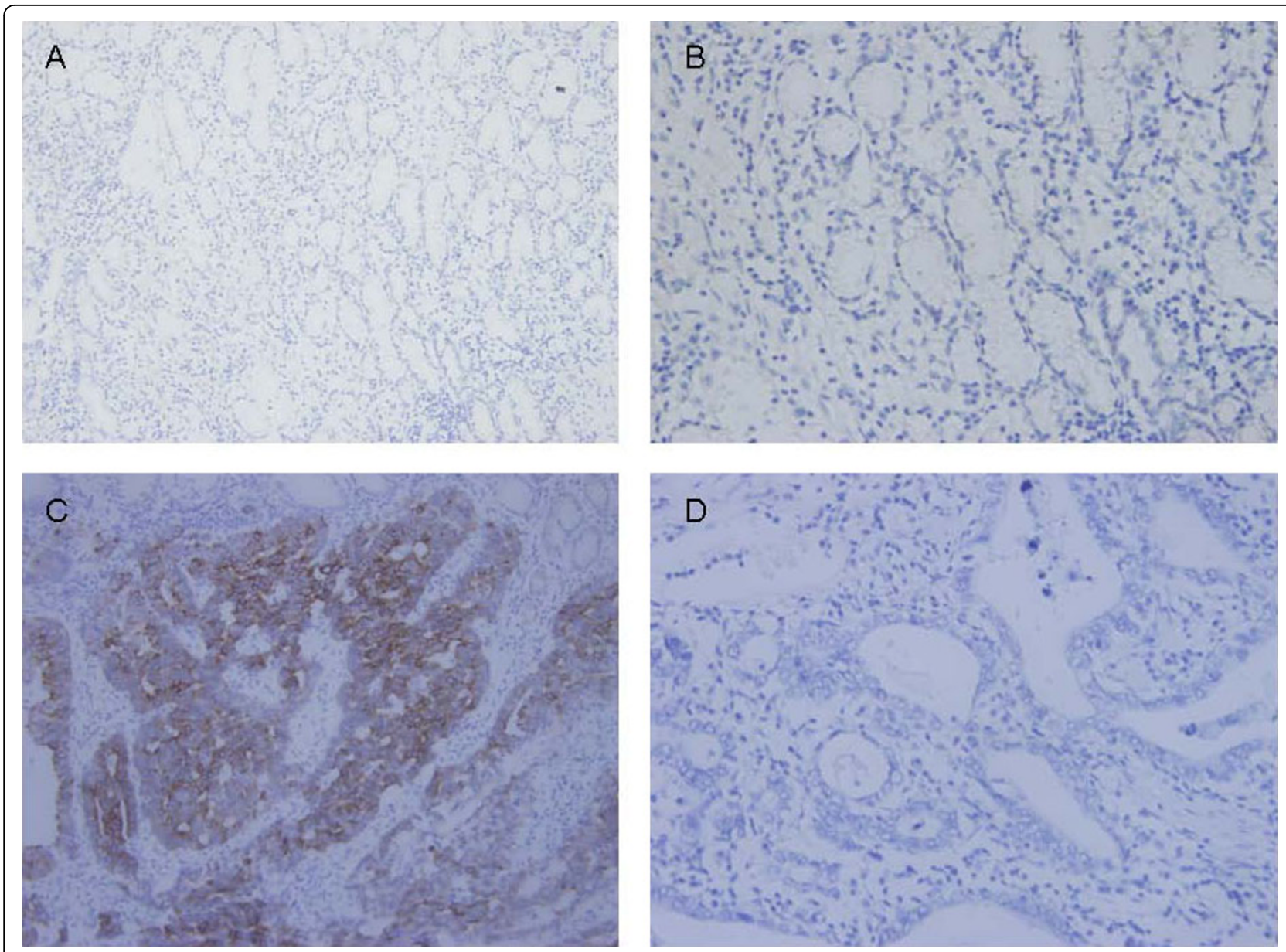

Figure 1 Examples of p-mTOR immunostaining. (A) The normal gastric mucosa is negative for $p$-mTOR (original magnification $\times 200$ ). (B) The normal gastric mucosa is negative for p-mTOR (original magnification $\times 400)(C)$ Positive expression of $p$-mTOR in gastric cancer (original magnification $\times 200$ ). (D) Negative expression of $p$-mTOR in gastric cancer (original magnification $\times 200$ ).

The mTOR protein forms a complex with adaptor proteins, mTORC1 (mammalian target of rapamycin complex 1) and mTORC2. Activation of mTORC1 regulates cell growth by modulating protein synthesis, ribosome biogenesis and autophagy [29]. The mTORC2 pathway plays a key part of activating Akt, like PDK1(3-phosphoinositide-dependent protein kinase 1) and PI3K, a potential drug target for cancers in which there is Akt deregulation [26].

In the current study, we observed that 93 (51.4\%) patients had positive expression of p-mTOR in 181 gastric cancer patients. Consistent with our result, in another study including 1072 patients, the expression of p-mTOR is $46.5 \%$ [30].

Previous studies have reported the prognostic significance of p-mTOR expression. Herberger et al [18]. identified p-mTOR to be an independent prognostic factor for death in patients with biliary tract adenocarcinoma. In their study, overall survival was significantly shorter in patients with p-mTOR-positive tumors as compared with patients with $\mathrm{p}$-mTOR-negative tumors $(\mathrm{P}=.004)$. In gastric cancer, Yu et al. evaluated expression of $\mathrm{p}$ mTOR in 1,072 gastric cancer patients using a tissue microarray, demonstrating overexpression of p-mTOR was an independent prognostic factor [30]. However, in a study included 109 patients with gastric adenocarcinomas who underwent a radical gastrectomy [31], Murayama et al. found neither cytoplasmic p-mTOR nor nuclear p-mTOR was independent prognostic factor, although they identified cytoplasmic p-mTOR expression was associated with poorer survival and correlated with the depth of tumour invasion, lymph nodes and tumour stage. In the present study, we confirmed that pT classification and lymph node status are independent prognostic indicator of clinical outcome in gastric cancer patients by multivariable analyses. However, because most patients present with locally advanced disease, other secondary prognostic markers, particularly 
Table 2 Univariable analysis of disease-free and overall survival in gastric cancer

\begin{tabular}{|c|c|c|c|c|c|c|c|}
\hline \multirow[b]{2}{*}{ Characteristic } & \multirow[b]{2}{*}{ No. } & \multicolumn{3}{|c|}{ Disease-free suivival } & \multicolumn{3}{|c|}{ Overall survival } \\
\hline & & HR & $95 \% \mathrm{Cl}$ & $p$ & HR & $95 \% \mathrm{Cl}$ & $p$ \\
\hline Age(y) & & & & .343 & & & .583 \\
\hline$<60$ & 95 & 1.00 & & & 1.00 & & \\
\hline$\geq 60$ & 86 & 0.834 & $0.573-1.214$ & & 0.898 & $0.611-1.320$ & \\
\hline Sex & & & & .662 & & & .950 \\
\hline Male & 129 & 1.00 & & & 1.00 & & \\
\hline Female & 52 & 0.909 & $0.591-1.396$ & & 0.986 & $0.639-1.521$ & \\
\hline Tumor size & & & & .151 & & & .232 \\
\hline$\leq 4 \mathrm{~cm}$ & 63 & 1.00 & & & 1.00 & & \\
\hline$>4 \mathrm{~cm}$ & 118 & 1.345 & $0.897-2.016$ & & 1.287 & $0.851-1.945$ & \\
\hline pT stage & & & & .001 & & & .005 \\
\hline pT1 & 17 & 1.00 & & & 1.00 & & \\
\hline pT2 & 35 & 1.549 & $0.558-4.301$ & .401 & 1.535 & $0.553-4.264$ & .411 \\
\hline pT3 & 119 & 3.546 & $1.437-8.750$ & .006 & 3.237 & $1.310-8.001$ & .011 \\
\hline pT4 & 10 & 4.738 & $1.547-14.506$ & .006 & 4.068 & $1.289-12.836$ & .017 \\
\hline pN stage & & & & $<.0001$ & & & .001 \\
\hline Negative & 44 & 1.00 & & & 1.00 & & \\
\hline Positive & 137 & 2.617 & $1.538-4.451$ & & 2.389 & $1.401-4.075$ & \\
\hline pTNM stage & & & & $<.0001$ & & & .001 \\
\hline I & 26 & 1.00 & & & 1.00 & & \\
\hline$\|$ & 47 & 2.920 & $1.197-7.121$ & .018 & 2.860 & $1.173-6.973$ & .021 \\
\hline III & 100 & 4.955 & $2.152-11.409$ & $<.0001$ & 4.455 & $1.930-10.281$ & $<.0001$ \\
\hline IV & 8 & 7.369 & $2.470-21.981$ & $<.0001$ & 6.103 & $1.965-18.957$ & .002 \\
\hline p-mTOR & & & & .008 & & & .013 \\
\hline Negative & 88 & 1.00 & & & 1.00 & & \\
\hline Positive & 93 & 1.667 & $1.146-2.454$ & & 1.644 & $1.112-2.430$ & \\
\hline
\end{tabular}

p-mTOR, may be of use [13]. Our results clearly show that $\mathrm{p}-\mathrm{mTOR}$ expression is correlated strongly with poor overall and disease-free survival in univariable analyses with a trend toward correlation in multivariable analyses.

Consistent with our current study, several studies have also recognized the antiproliferative effects of mTOR inhibitors in gastric cancer cells. For example, Lang et al [21]. identified rapamycin could inhibit gastric cancer cell growth in both a subcutaneous tumor model and in an experimental model. Their results highlight the suitability of mTOR inhibitors to be used in an antiangiogenic context for therapy of gastric cancer.

However, RAD001 is a new mTOR inhibitor as anticancer agent. The mechanism about RAD001 in gastric cancer is not clear. Cejka et al. showed the antiangiogenic activity of RAD001 combined with a high dose of cyclophosphamide revealed synergistic antitumor activity against gastric cancer [32]. They have also found that RAD001 decreased proliferation and attenuated production of HIF- $1 \alpha$ as well as VEGF in gastric cancer cells in vitro [33]. In the current study, our data showed that RAD001-therapy attenuated phosphorylation of p70S6K and markedly inhibited the proliferation of gastric cancer cells through cell-cycle arrest and apoptosis in vitro. We found RAD001 induced the G0/G1 phase arrest, which was associated with decreased cyclin D1 and C-myc. Moreover, we showed for the first time that RAD001 as a new mTOR inhibitor dose-dependently induced apoptosis in gastric cancer cells by Annexin V assays. This effect may be dictated by the cellular context and downstream targets including P53 and Bcl-2. These findings might further explain the efficacy of RAD001.

\section{Conclusion}

In summary, we conducted systematical research to mTOR in gastric cancer, indicating the relationships the expression with the prognosis value of activated mTOR (p-mTOR) in vivo, the effect of RAD001 and the part of mechanisms in gastric cancer cells in vitro. Our findings indicated that p-mTOR would serve as a potential biological marker to identify a subgroup of gastric cancer patients of poor prognosis. It also showed that RAD001 was a promising agent for the treatment of gastric cancer with inducing cell cycle arrest and apoptosis by down-regulating expression of C-myc, CyclinD1 and Bcl-2, up-regulating expression of P53. Further studies 

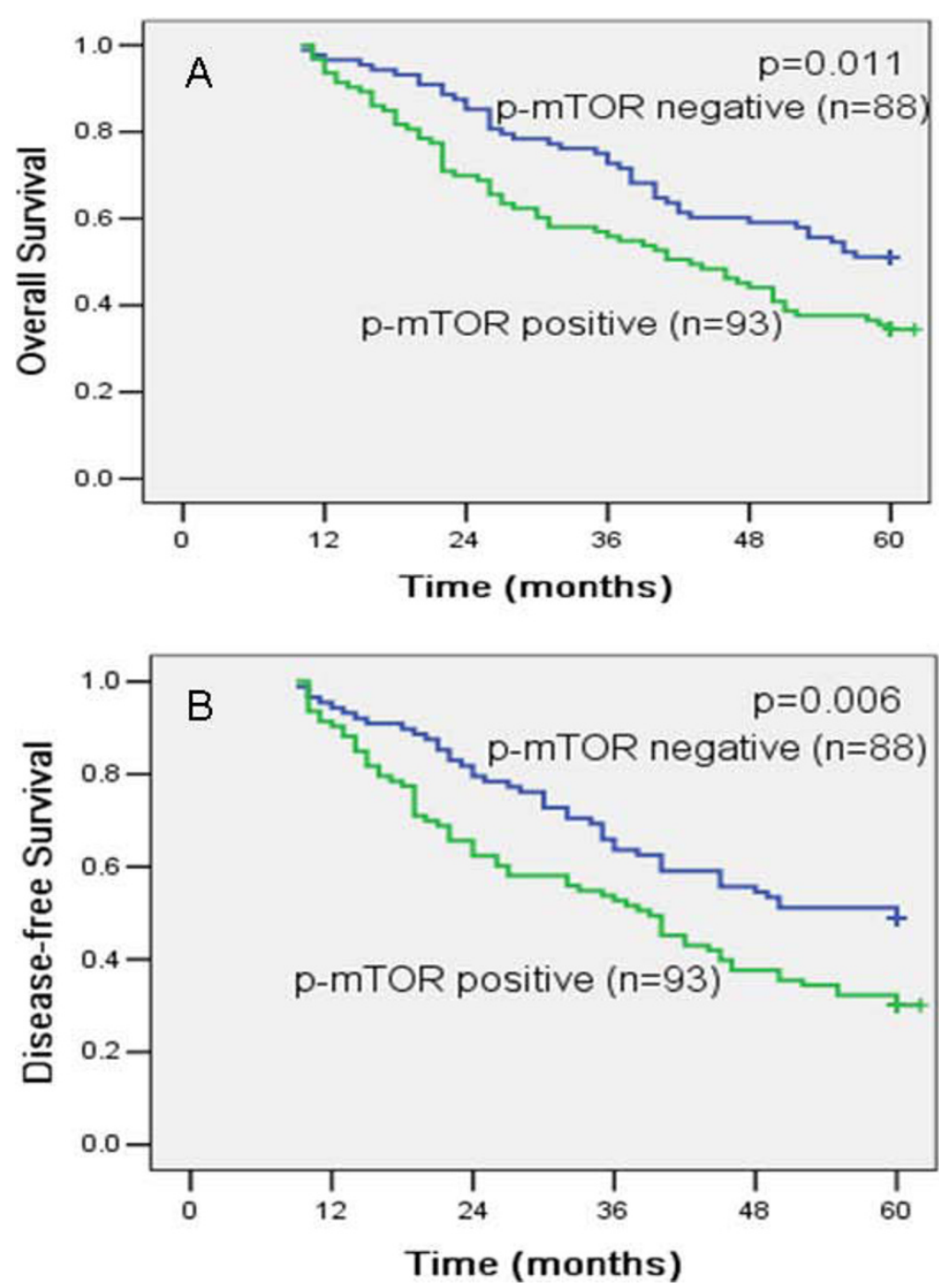

Figure 2 Kaplan-Meier estimates of the probability of survival. Patients with p-mTOR positive showed significantly shorter overall survival (A) and disease-free survival (B) rates than those with $p$-mTOR negative expression. ( $p=.011$ and $p=.006$, respectively).

Table 3 Multivariable cox regression analysis of disease-free and overall survivals

\begin{tabular}{|c|c|c|c|c|c|c|c|}
\hline \multirow[b]{2}{*}{ Factors } & \multirow[b]{2}{*}{ No. } & \multicolumn{3}{|c|}{ Disease-free suivival } & \multicolumn{3}{|c|}{ Overall survival } \\
\hline & & $\mathrm{HR}$ & $95 \% \mathrm{Cl}$ & $p$ & HR & $95 \% \mathrm{Cl}$ & $p$ \\
\hline p-mTOR & & & & 0.059 & & & 0.070 \\
\hline Negative & 88 & 1.00 & & & 1.00 & & \\
\hline Positive & 93 & 1.452 & $0.986-2.138$ & & 1.443 & $0.970-2.147$ & \\
\hline Infiltrating depth & & & & 0.018 & & & 0.046 \\
\hline pT1 & 17 & 1.00 & & & 1.00 & & \\
\hline pT2 & 35 & 1.050 & $0.366-3.016$ & 0.928 & 1.078 & $0.375-3.101$ & 0.88 \\
\hline pT3 & 119 & 2.251 & $0.867-5.845$ & 0.096 & 2.146 & $0.823-5.595$ & 0.118 \\
\hline pT4 & 10 & 2.926 & $0.920-9.305$ & 0.069 & 2.616 & $2.616-8.580$ & 0.113 \\
\hline Lymph node status & & & & 0.018 & & & 0.038 \\
\hline Negative & 44 & 1.00 & & & 1.00 & & \\
\hline Positive & 137 & 1.981 & $1.981-3.488$ & & 1.828 & $1.034-3.233$ & \\
\hline
\end{tabular}




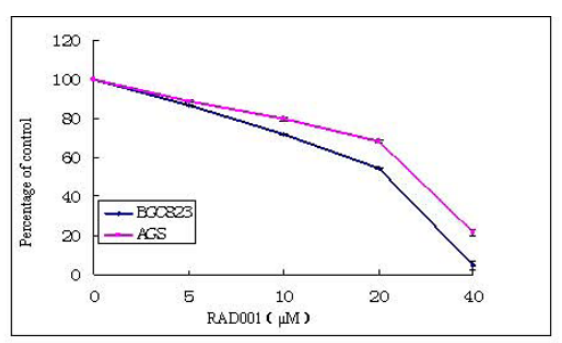

AGS

A
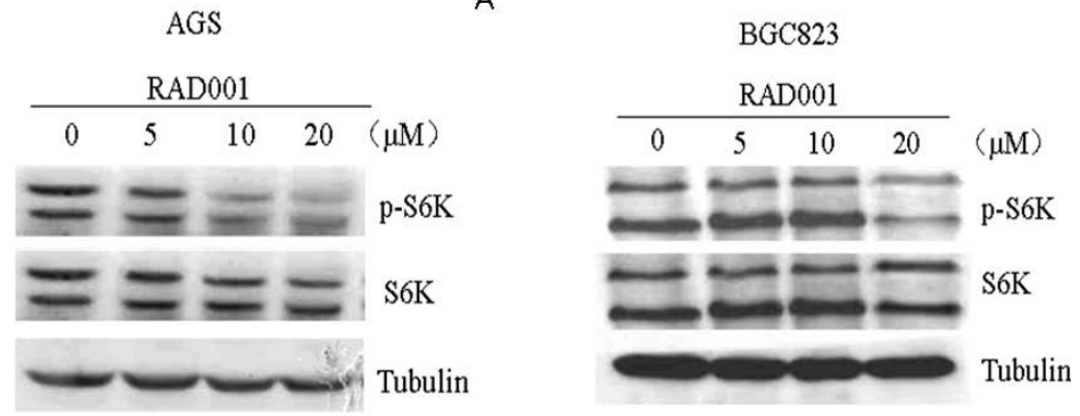

B

Figure 3 (A) RAD001 inhibits proliferation of gastric cancer cells. Gastric cancer cells were treated with the indicated concentrations of RAD001 in the presence of 10\% FBS for 48 h. Cell viability was assessed by MTT assay. (B) Phosphorylation of p70s6K was significantly decreased in a dose-dependent manner in both AGS and BGC823 cells by the treatment with RAD001. Both cell lines were incubated with increasing dose of RAD001 for 48 hrs, cell lysates were subjected to western blot analysis with phosphorylated p-S6K and S6K antibodies.

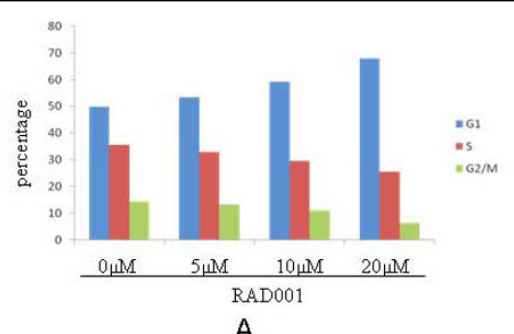

A

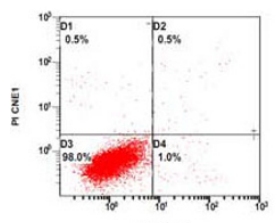

RAD001 OMM

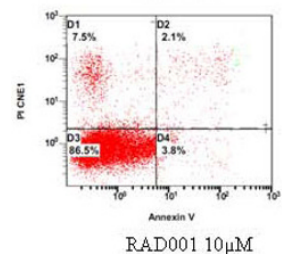

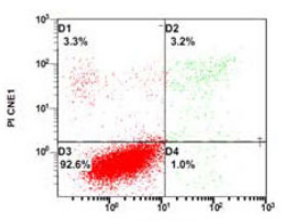

RAD0015 $5 \mu \mathrm{M}$

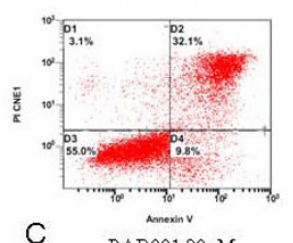

RAD001

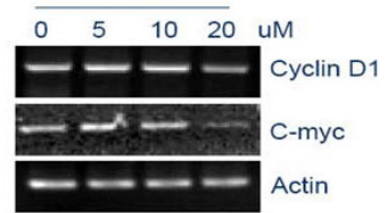

B

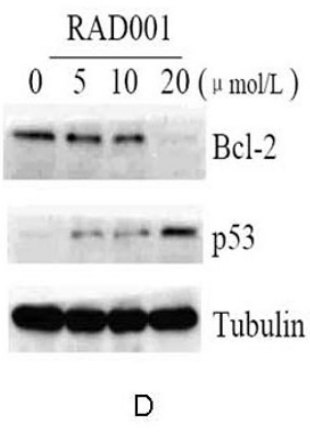

Figure 4 RAD001 induces cell cycle arrest and apoptosis in BGC823 cells. (A) BGC823 cells were exposed to various concentrations of RAD001 for 48 h. (B) RNA were extracted from cells. Cyclin D1 and C-myc expression level were detected by RT-PCR, actin as a loading control. (C) cells were incubated for 48 hrs with indicated doses of RAD001 before staining with annexin V-FITC. The percentages of apoptotic cells are displayed. (D) Cells were incubated for 48 hrs with indicated doses of RAD001. Cells were collected, lysed and subjected to Western blot analysis with $\mathrm{BCl}-2$ and $\mathrm{p} 53$ antibodies. GAPDH was used as a loading control. 
are required to elucidate the role of the activation of mTOR and eventually to propose mTOR as a concrete target for gastric cancer therapy.

\section{Note}

Grant Support: Supported by National High Technology Research and Development (863) Program of China

\section{Acknowledgements}

This work was supported by National High Technology Research and Development (863) Program of China. The authors appreciate the excellent technical assistance of Li-hui Wang, Fei-meng Zheng, Zheng-zhi Zou, Yan Zhang and Zi-jie Long.

\section{Author details}

'State Key Laboratory of Oncology in South China, Guangzhou 510060, China. ${ }^{2}$ Department of Gastric \& pancreatic Surgery, Cancer Center, Sun Yatsen University, Guangzhou 510060, China. ${ }^{3}$ Department of Medical Oncology, Cancer Center, Sun Yat-sen University, Guangzhou 510060, China. ${ }^{4}$ Department of Pathology, Cancer Center, Sun Yat-sen University, Guangzhou 510060, China. ${ }^{5}$ Department of Pathology, the Sixth Affiliated Hospital, Sun Yat-sen University, Guangzhou 510060, China.

\section{Authors' contributions}

DZX and QRG designed the research, final data analysis and drafted the manuscript. YT carried out the molecular studies. XJF and MYC assessed all slides independently. ZWZ, WL, YBC, XWS, YXG and YFL collected the gastric cancer tissues. TYL and YQZ supervised all the work. All authors read and approved the final version of the manuscript.

\section{Competing interests}

The authors declare that they have no competing interests.

Received: 20 September 2009 Accepted: 7 October 2010 Published: 7 October 2010

\section{References}

1. Jemal A, Siegel R, Ward E, Murray T, Xu J, Smigal C, Thun MJ: Cancer statistics.2006. CA Cancer J Clin 2006, 56(2):106-30.

2. Sasako M, Sano T, Yamamoto S, Kurokawa $Y$, Nashimoto A, Kurita A Hiratsuka M, Tsujinaka T, Kinoshita T, Arai K, et al: D2 lymphadenectomy alone or with para-aortic nodal dissection for gastric cancer. $N$ Engl J Med 2008, 359(5):453-62.

3. Liu TS, Wang Y, Chen SY, Sun YH: An updated meta-analysis of adjuvant chemotherapy after curative resection for gastric cancer. Eur J Surg Oncol 2008, 34(11):1208-16.

4. Hohenberger P, Gretschel S: Gastric cancer. Lancet 2003, 362(9380):305-15.

5. Dicken BJ, Bigam DL, Cass C, Mackey JR, Joy AA, Hamilton SM: Gastric adenocarcinoma: review and considerations for future directions. Ann Surg 2005, 241(1):27-39.

6. Xu DZ, Geng QR, Long ZJ, Zhan YQ, Li W, Zhou ZW, Chen YB, Sun XW, Chen G, Liu Q: Positive Lymph Node Ratio Is an Independent Prognostic Factor in Gastric Cancer After D2 Resection Regardless of the Examined Number of Lymph Nodes. Ann Surg Oncol 2009, 16(2):319-26.

7. Xu DZ, Zhan YQ, Sun XW, Cao SM, Geng QR: Meta-analysis of intraperitoneal chemotherapy for locally advanced gastric cancer. World J Gastroenterol 2004, 10(18):2727-30.

8. Sutter AP, Zeitz M, Scherübl H: Recent results in understanding molecular pathways in the medical treatment of esophageal and gastric cancer. Onkologie 2004, 27(1):17-21.

9. Galizia G, Ferraraccio F, Lieto E, Orditura M, Castellano P, Imperatore V, La Manna G, Pinto M, Ciardiello F, La Mura A, et al: p27 downregulation and metallothionein overexpression in gastric cancer patients are associated with a poor survival rate. J Surg Oncol 2006, 93(3):241-52.

10. Lieto E, Ferraraccio F, Orditura M, Castellano P, Mura AL, Pinto M, Zamboli A, De Vita F, Galizia G: Expression of vascular endothelial growth factor (VEGF) and epidermal growth factor receptor (EGFR) is an independent prognostic indicator of worse outcome in gastric cancer patients. Ann Surg Oncol 2008, 15(1):69-79.

11. Galizia G, Lieto E, Orditura M, Castellano P, Mura AL, Imperatore V, Pinto M, Zamboli A, De Vita F, Ferraraccio F: Epidermal growth factor receptor (EGFR) expression is associated with a worse prognosis in gastric cancer patients undergoing curative surgery. World J Surg 2007, 31(7):1458-68.

12. García I, Vizoso F, Martín A, Sanz L, Abdel-Lah O, Raigoso P, García-Muñiz JL: Clinical significance of the epidermal growth factor receptor and HER2 receptor in resectable gastric cancer. Ann Surg Oncol 2003, 10(3):234-41.

13. Wang KL, Wu TT, Choi IS, Wang H, Resetkova E, Correa AM, Hofstetter WL, Swisher SG, Ajani JA, Rashid A, et al: Expression of epidermal growth factor receptor in esophageal and esophagogastric junction adenocarcinomas: association with poor outcome. Cancer 2007, 109(4):658-67.

14. Oh SY, Kwon HC, Kim SH, Jang JS, Kim MC, Kim KH, Han JY, Kim CO, Kim SJ, Jeong JS, Kim HJ: Clinicopathologic significance of HIF-1alpha, p53, and VEGF expression and preoperative serum VEGF level in gastric cancer. BMC Cancer 2008, 1(8):123.

15. Zhou D, Pan G, Zheng C, Zheng J, Yian L, Teng X: Expression of the RON receptor tyrosine kinase and its association with gastric carcinoma versus normal gastric tissues. BMC Cancer 2008, 28(8):353.

16. Sahin F, Kannangai R, Adegbola O, Wang J, Su G, Torbenson M: mTOR and P70 S6 kinase expression in primary liver neoplasms. Clin Cancer Res 2004, 10(24):8421-5.

17. Noh WC, Kim YH, Kim MS, Koh JS, Kim HA, Moon NM, Paik NS: Activation of the mTOR signaling pathway in breast cancer and its correlation with the clinicopathologic variables. Breast Cancer Res Treat 2008, 110(3):477-83.

18. Herberger B, Puhalla $H$, Lehnert M, Wrba F, Novak S, Brandstetter A, Gruenberger B, Gruenberger T, Pirker R, Filipits M: Activated mammalian target of rapamycin is an adverse prognostic factor in patients with biliary tract adenocarcinoma. Clin Cancer Res 2007, 13(16):4795-9.

19. Faried LS, Faried A, Kanuma T, Sano T, Nakazato T, Tamura T, Kuwano H, Minegishi T: Predictive and prognostic role of activated mammalian target of rapamycin in cervical cancer treated with cisplatin-based neoadjuvant chemotherapy. Oncol Rep 2006, 16(1):57-63.

20. Faried LS, Faried A, Kanuma T, Aoki H, Sano T, Nakazato T, Tamura T, Kuwano $H$, Minegishi $T$ : Expression of an activated mammalian target of rapamycin in adenocarcinoma of the cervix: A potential biomarker and molecular target therapy. Mol Carcinog 2008, 47(6):446-57.

21. Lang SA, Gaumann A, Koehl GE, Seidel U, Bataille F, Klein D, Ellis LM, Bolder U, Hofstaedter F, Schlitt HJ, et al: Mammalian target of rapamycin is activated in human gastric cancer and serves as a target for therapy in an experimental model. Int J Cancer 2007, 120(8):1803-10.

22. Motzer RJ, Escudier B, Oudard S, Hutson TE, Porta C, Bracarda S, Grünwald V, Thompson JA, Figlin RA, Hollaender N, et al: Efficacy of everolimus in advanced renal cell carcinoma: a double-blind, randomised, placebo-controlled phase III trial. Lancet 2008, 372(9637):449-56

23. Majumder PK, Febbo PG, Bikoff R, Berger R, Xue Q, McMahon LM, Manola J, Brugarolas J, McDonnell TJ, Golub TR, et al: mTOR inhibition reverses Aktdependent prostate intraepithelial neoplasia through regulation of apoptotic and HIF-1-dependent pathways. Nat Med 2004, 10(6):594-601.

24. Beuvink I, Boulay A, Fumagalli S, Zilbermann F, Ruetz S, O'Reilly T, Natt F, Hall J, Lane HA, Thomas G: The mTOR inhibitor RAD001 sensitizes tumor cells to DNA-damaged induced apoptosis through inhibition of p21 translation. Cell 2005, 120(6):747-59.

25. Ning X, Yang S, Wang R, Zhang R, Guo L, Tie J, Cheng Y, Wang G, Wan S, Fang D: POT1 deficiency alters telomere length and telomere-associated gene expression in human gastric cancer cells. Eur J Cancer Prev 2010, 19(5):345-51.

26. Sobin $\mathrm{LH}$, Wittenkind $\mathrm{CH}$ : International Union Against Cancer: TNM Classification of Malignant Tumors New York: John Wiley-Liss, 62002.

27. Sabatini DM: mTOR and cancer: insights into a complex relationship. Nat Rev Cancer 2006, 6(9):729-34.

28. Brown EJ, Albers MW, Shin TB, Ichikawa K, Keith CT, Lane WS, Schreiber SL A mammalian protein targeted by G1-arresting rapamycin-receptor complex. Nature 1994, 369(6483):756-8.

29. Wullschleger $S$, Loewith $R$, Hall MN: TOR signaling in growth and metabolism. Cell 2006, 124(3):471-84

30. Yu G, Wang J, Chen Y, Wang X, Pan J, Li G, Jia Z, Li Q, Yao JC, Xie K: Overexpression of phosphorylated mammalian target of rapamycin 
predicts lymph node metastasis and prognosis of chinese patients with gastric cancer. Clin Cancer Res 2009, 15(5):1821-9.

31. Murayama T, Inokuchi M, Takagi Y, Yamada H, Kojima K, Kumagai J,

Kawano T, Sugihara K: Relation between outcomes and localisation of $p$ mTOR expression in gastric cancer. Br J Cancer 2009, 100(5):782-8.

32. Cejka D, Preusser M, Fuereder T, Sieghart W, Werzowa J, Strommer S, Wacheck V: mTOR inhibition sensitizes gastric cancer to alkylating chemotherapy in vivo. Anticancer Res 2008, 28(6A):3801-8.

33. Cejka D, Preusser M, Woehrer A, Sieghart W, Strommer S, Werzowa J, Fuereder T, Wacheck V: Everolimus (RAD001) and anti-angiogenic cyclophosphamide show long-term control of gastric cancer growth in vivo. Cancer Biol Ther 2008, 7(9):1377-85.

\section{Pre-publication history}

The pre-publication history for this paper can be accessed here: http://www.biomedcentral.com/1471-2407/10/536/prepub

doi:10.1186/1471-2407-10-536

Cite this article as: Xu et al:: Activated mammalian target of rapamycin is a potential therapeutic target in gastric cancer. BMC Cancer 2010 10:536

\section{Submit your next manuscript to BioMed Central} and take full advantage of:

- Convenient online submission

- Thorough peer review

- No space constraints or color figure charges

- Immediate publication on acceptance

- Inclusion in PubMed, CAS, Scopus and Google Scholar

- Research which is freely available for redistribution

Submit your manuscript at www.biomedcentral.com/submit 